\begin{tabular}{|l|l|l|l|l|l|}
\hline J. Tek. Ling & Vol. 10 & No. 2 & Hal. 121 - 228 & Jakarta, Mei 2009 & ISSN 1441-318X \\
\hline
\end{tabular}

\title{
HYBRID SOLAR LIGHTING SEBAGAI ALTERNATIF TEKNOLOGI PENERANGAN ALAMI BANGUNAN UNTUK EFISIENSI ENERGI DAN PEMANFAATAN ENERGI TERBARUKAN
}

\author{
Suryo Anggoro \\ Peneliti di Pusat Teknologi Lingkungan \\ Badan Pengkajian dan Penerapan Teknologi
}

\begin{abstract}
Artificial (electric) and direct lighting technologies available today have the potential to greatly reduce the growth rate of electricity consumed through lighting worldwide. While electric lighting has been inefficient throughout much of its history, direct (natural) lighting is nearly free and often plentifully supplied by the sun. However, electric lighting systems are necessary when solar lighting is not adequate and these technologies are being greatly improved.

One relatively new method of lighting a building's interior combines both artificial and direct lighting to maximize efficiency is accomplished through the use of a paraboloidal, mirrored dish which actively tracks the sun to concentrate sunlight into an array of fiber optics.
\end{abstract}

Key words : solar lighting, fiber optics

\section{PENDAHULUAN}

\subsection{Latar Belakang}

Setelah ditemukannya pencahayaan buatan yang menggunakan sumber energi listrik secara efisien dan murah di pertengahan abad ke-20, pencahayaan alami dari cahaya matahari menjadi tergantikan fungsinya sebagai sumber penerangan interior bangunan. Penerangan listrik merubah persepsi arsitektur tentang pencahayaan dalam ruangan sehingga mengarah pada ketergantungan pada sumber penerangan listrik, seperti yang terjadi dewasa ini. Namun penggunaan penerangan listrik semakin mengarah pada non efisiensi dan pemborosan. Kecenderungan yang terjadi di hampir semua negara sekitar
$25 \%$ dari energi listrik yang dihasilkan digunakan untuk penerangan ${ }^{1}$. Ketika terjadi keterbatasan sumber energi, upaya penghematan energi menjadi sebuah keharusan, termasuk upaya efisiensi untuk penerangan bangunan.

Upaya-upaya efisiensi untuk penerangan bangunan telah dilakukan antara lain melalui penggunaan lampu hemat energi atau pemanfaatan photovoltaic serta modifikasi fasad, jendela dan bukaan dinding bangunan. Kecenderungan yang dilakukan dewasa ini adalah kembali menggunakan sumber cahaya matahari sebagai sumber penerangan. Walaupun sumber cahaya matahari sebagai sumber penerangan memiliki aspek akumulasi panas sebagai efek penyertanya ${ }^{2)}$. 
Pencahayaan alami melalui jendela dan bukaan dinding bangunan juga membawa efek samping yang tidak diinginkan seperti silau, pembiasan cahaya dan panas/kalor yang memiliki pengaruh pada peningkatan suhu ruangan.

Bahan serat optik atau fiber optic ditemukan pada akhir abad 20 dan berdasarkan riset dan penelitian yang telah dilakukan berfungsi sebagai media penghantar gelombang optik, termasuk cahaya.

\subsection{Tujuan}

Tulisan ini berusaha mengkaji efektifitas fiber optik yang menggunakan prinsip hantaran cahaya untuk digunakan sebagai alternatif penerangan yang memanfaatkan cahaya alami matahari, khususnya di Indonesia.

\section{TINJAUAN PUSTAKA}

Hybrid solar lighting atau penerangan hibrid dengan energi matahari adalah penemuan baru di bidang penggunaan energi matahari. Teknologi ini berbeda dengan panel surya atau photovoltaic yang mengumpulkan energi matahari, mengkonversinya menjadi energi listrik dan menyimpannya untuk kemudian digunakan sebagai sumber listrik penerangan di dalam bangunan. Penerangan hibrid matahari mentransmisikan cahaya matahari langsung ke dalam bangunan sebagai penerangan melalui media kabel serat optik atau fiber optic, seperti halnya listrik dihantarkan melalui kabel.

Proses transmisi energi matahari dengan teknologi hibrid menjadi lebih efisien karena tidak memerlukan proses konversi energi. Muhs (2000) dan beberapa riset yang telah dilakukan menyebutkan bahwa panel surya memiliki kemampuan memanfaatkan cahaya matahari yang diterima sebesar 15\% karena terjadi proses konversi cahaya menjadi listrik. Penerangan dengan teknolgi hibrid mampu memanfaatkan cahaya matahari yang diterima hingga $50 \%{ }^{3}$.
Teknologi pemanfaatan media serat optik sebagai penghantar cahaya matahari telah dimulai sejak tahun 1979 di Jepang melalui proyek Himawari. Dengan semakin intensifnya riset dan penelitian lanjutan yang dilakukan maka media serat optik yang dipergunakan menjadi semakin efisien dan murah. Bahan serat optik yang semula menggunakan bahan serat kaca yang mahal kemudian menggunakan bahan serat plastik fiber yang lebih murah. Prototipe teknologi penerangan hibrid mulai diaplikasikan dan digunakan untuk kebutuhan penerangan komersial di tahun 2002 melalui riset yang dilakukan Oak Ridge National Laboratory4).

Cahaya matahari yang ditransmisikan dengan teknologi hibrid merupakan cahaya terkonsentrasi dengan tingkat intensitas tinggi yang diperoleh melalui prinsip penangkapan cahaya. Alat penangkap cahaya yang dipergunakan adalah piringan cermin berbentuk parabola (gambar 1,2 \& 3).

Cahaya matahari yang jatuh pada permukaan cermin parabola akan dipantulkan secara terarah ke bagian atas tengah parabola dan kemudian ditangkap oleh cermin kedua yang berada di atas parabola. Cermin kedua ini memiliki fungsi untuk memfokuskan titik cahaya matahari yang jatuh pada penampang serat optik.

Serat optik yang dipergunakan untuk menghantarkan cahaya memiliki ukuran penampang sebesar $12 \mathrm{~mm}$ dan terbuat dari bahan plasti fiber. Namun serat optik ukuran standar dengan penampang $3 \mathrm{~mm}$ yang dibuat oleh industri manufaktur pada umumnya secara fungsional adalah sama $^{5,6,7)}$.

Parabola yang dipergunakan pada prototipe awal menggunakan bahan kaca utuh yang dibentuk dan sangat mahal. Namun prototipe selanjutnya menggunakan parabola dengan bahan plastik dengan pelapis cermin yang murah dan ringan ${ }^{5,6)}$. 


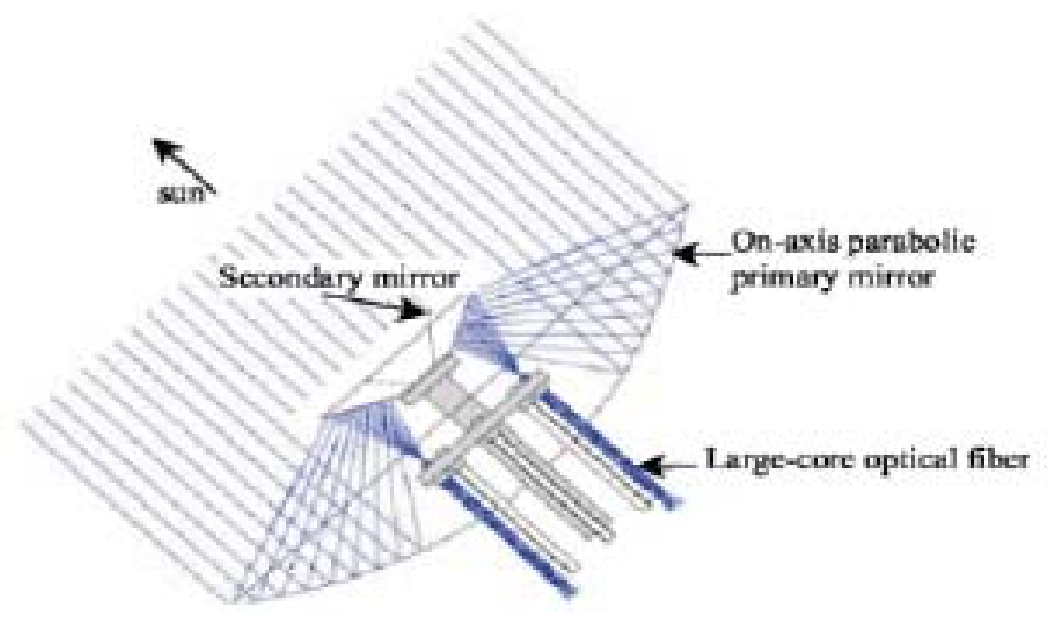

Gambar.1. Piringan cermin parabola

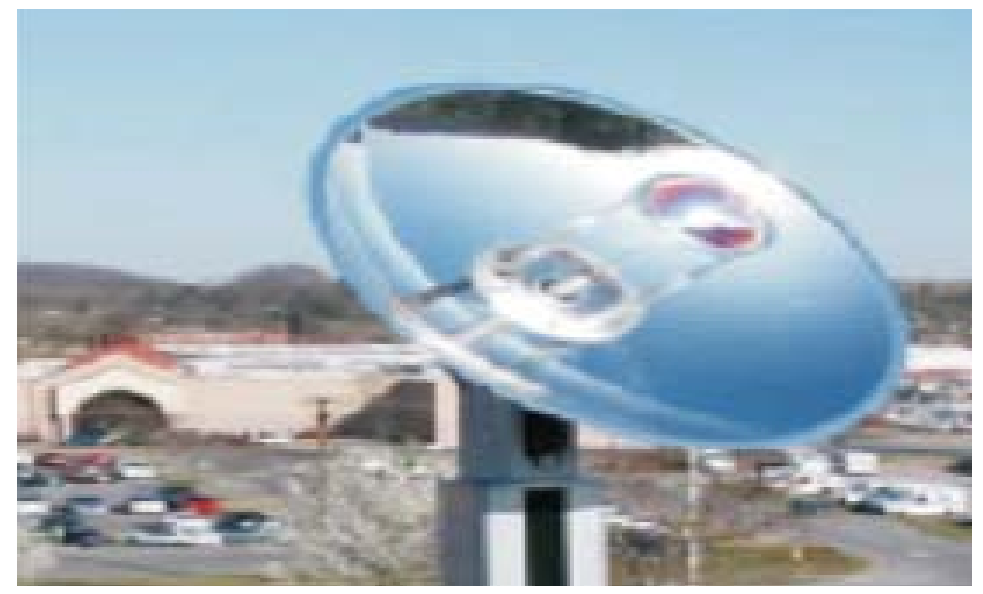

Gambar. 2. Prototipe parabola

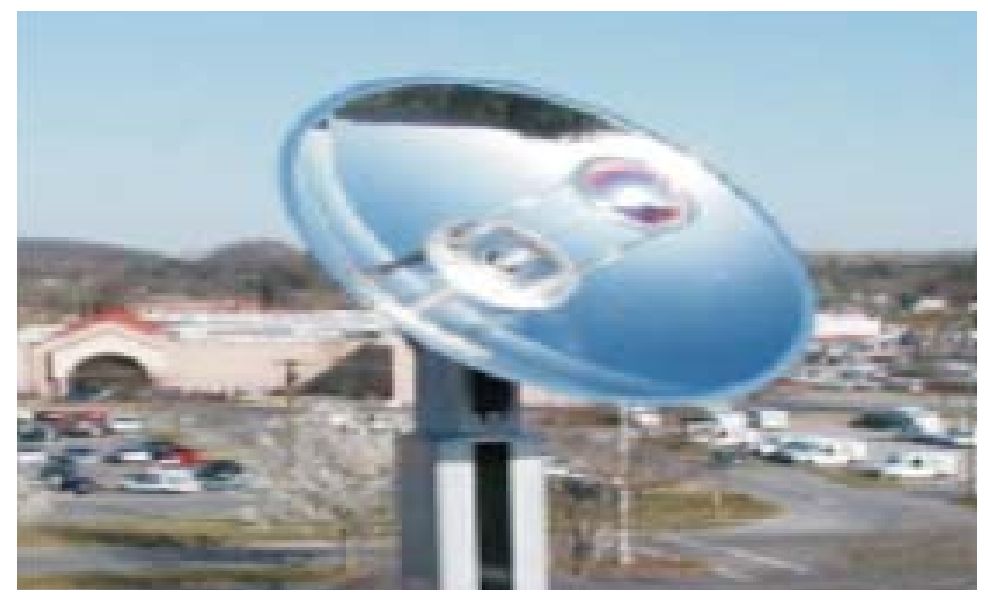

Gambar. 3. Prototipe parabola

Hybrid Solar Light Sebagai...J. Tek. Ling.10 (2): 121 - 128 
Kekuatan cahaya yang dihantarkan dan di transmisikan oleh serat optik hampir setara dengan kekuatan cahaya alami matahari dengan temperatur warna sebesar $6000^{\circ} \mathrm{K}$ dan berdasarkan hasil riset yang dilakukan oleh Lapsa, Ward dan Maxey kabel fiber optik dapat menghantarkan cahaya dengan keluaran intensitas sebesar 50.000 lumen dan spektrum warna yang utuh (380nm-730nm) serta tanpa sinar ultraviolet ${ }^{5}$. Karena sinar ultraviolet tidak ikut ditransmisikan maka efek positif yang terjadi adalah tidak ada hantaran panas atau kalor yang menyertai cahaya matahari yang ditransmisikan.

Kemampuan transmisi cahaya media serat optik sesuai dengan hasil penelitian Muhs dan Woods ternyata dipengaruhi oleh faktor panjang kabel serat optik. Hal ini terutama akibat pengaruh bahan, dan lapisan pelindung serat optik. Hasil penelitian menunjukkan kemampuan transmisi mempunyai penurunan rata-rata sebesar $15 \%$ per meter panjang ${ }^{8)}$ dengan hasil seperti pada tabel 1 :

Intensitas cahaya yang mampu ditransmisikan serat optik sebesar 50.000 lumen mampu untuk memenuhi kebutuhan penerangan ruangan seluas $1000 \mathrm{ft}^{2}$ atau
Tabel 1. Hasil Uji Transmisi kabel serat optik (sumber: Muhs dan Wood, 2004)

\begin{tabular}{|c|c|c|}
\hline $\begin{array}{c}\text { Panjang } \\
\text { Fiber (m) }\end{array}$ & $\begin{array}{c}\text { Transmisi } \\
\text { (lumen) }\end{array}$ & $\begin{array}{c}\text { Temp. warna } \\
\text { (k) }\end{array}$ \\
\hline 4,5 & 5709 & 5033 \\
\hline 5,5 & 5516 & 5073 \\
\hline 6,5 & 5324 & 5111 \\
\hline 7,5 & 5132 & 5250 \\
\hline 8,5 & 4887 & 5182 \\
\hline 9,5 & 4791 & 5243 \\
\hline 10,5 & 4545 & 5298 \\
\hline
\end{tabular}

sekitar $93 \mathrm{~m}^{2}$. Dengan spektrum cahaya yang utuh maka kualitas cahaya untuk penerangan di dalam bangunan menjadi optimal, terutama memiliki efek pada persepsi warna ruang dan warna benda objek yang ada di dalam ruang.Perbandingan gelombang cahaya matahari dan cahaya yang ditransmisikan oleh serat optik ditunjukkan pada grafik di gbr.4. Dari grafik terlihat bahwa rentang panjang gelombang yang ditransmisikan oleh serat optik tidak jauh berbeda dengan cahaya matahari alami.

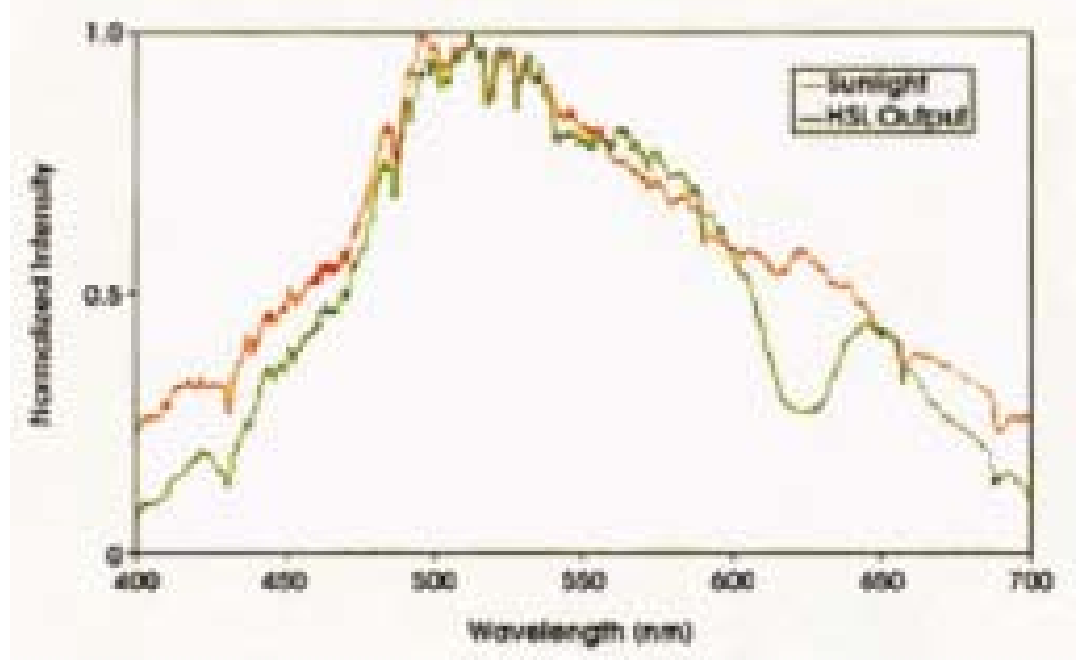

Gambar 4. Perbandingan Grafik Panjang Gelombang Cahaya Matahari dan Output Serat Optik (sumber: Maxey,2008) 
Sementara gelombang cahaya yang dihasilkan oleh lampu penerangan fluorescent standar menunjukkan panjang gelombang yang fluktuatif dan spektrum warna yang tidak utuh, seperti terlihat pada grafik di gbr.5.
3. Proses transmisi cahaya melalui media serat optik disalurkan dengan kabel, seperti halnya listrik. Tidak terjadi konversi energi, sehingga proses menjadi lebih efektif dan tidak terlalu rumit.

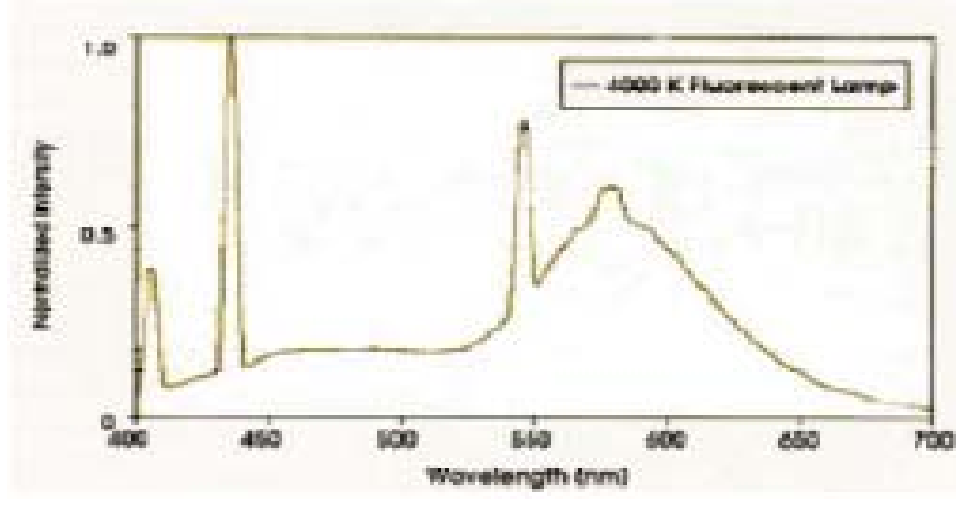

Gambar. 5. Grafik Panjang Gelombang Lampu Penerangan Fluorescent (sumber: Maxey, 2008)

\section{HASIL DAN PEMBAHASAN}

Teknologi penerangan hibrid yang menggunakan media serat optik sebagai penghantar cahaya matahari memiliki beberapa kelebihan dan efek positif sebagai berikut:

1. Hantaran panas atau kalor yang biasanya menyertai cahaya bisa ditiadakan sehingga bisa menghemat energi yang dipergunakan untuk pendinginan dalam bangunan, terutama di daerah tropis.

2. Spektrum utuh cahaya matahari yang ditransmisikan dan dikeluarkan tidak mengalami penurunan atau masih setara dengan cahaya alami matahari, sehingga kualitas cahaya untuk penerangan di dalam bangunan semakin baik. Hal ini terutama berguna bagi ruang-ruang arsitektur yang membutuhkan pencahayaan khusus seperti museum, galeri seni, rumah sakit, dan lain-lain.
4. Tidak ada konversi energi, tidak ada hantaran listrik, sehingga aplikasi penerangan hibrid dapat diterapkan secara aman untuk ruang-ruang arsitektur yang sensitif atau rawan bahaya, seperti laboratorium kimia, reaktor nuklir, instalasi bawah air, ruang penyimpanan senjata, dll. Hal ini meniadakan resiko terjadinya ledakan atau kebakaran akibat hubungan pendek arus listrik.

5. Sistem transmisi cahaya matahari yang sederhana dan tanpa konversi energi lanjutan, menyebabkan peralatan penerangan hibrid menjadi sederhana, tidak terlalu rumit, mudah dalam proses instalasi dan memudahkan proses perawatan sehingga efisiensi sumberdaya manusia dan biaya perawatan.

6. Peralatan penerangan hibrid yang tidak membutuhkan ruang yang besar dan proses instalasi yang sederhana, memudahkan untuk diaplikasikan 
pada bangunan yang sudah ada atau eksisting atau bangunan baru, tanpa merubah struktur bangunan.

7. Kekuatan cahaya yang ditransmisikan penerangan hibrid mampu mencapai 50000 lumen atau cukup untuk penerangan sebuah ruangan seluas $1000 \mathrm{ft}^{2}$ atau sekitar $93 \mathrm{~m}^{2}$. Kekuatan sebesar 50000 lumen setara dengan 55 buah lampu 60watt standar dan 75 buah lampu bohlam warna 60watt ${ }^{(4,5)}$. Dengan demikian bisa menghemat energi listrik hingga sebesar 5000watt atau $5 \mathrm{Kwh}$ per $90 \mathrm{~m}^{2}$ ruang.

8. Hasil perhitungan ekonomi yang dilakukan Soydan dan en Gin (2002) ${ }^{1)}$ dengan perbandingan ekonomi antara penerangan hibrid dan panel surya,

Tabel 2. Perbandingan Nilai Ekonomi dalam dollar Antara Penerangan Hibrid dengan Panel Surya (sumber: Soydan dan en Gin, 2002).

\begin{tabular}{|c|c|c|}
\hline Parameter & Hibrid & Photovoltaics \\
\hline Efisiensi & $50-70 \%$ & $5-12 \%$ \\
\hline $\begin{array}{c}\text { Instalasi } \\
\$ / \mathrm{Wp}\end{array}$ & $\$ 2.50 / \mathrm{Wp}$ & $\$ 10 / \mathrm{Wp}$ \\
\hline $\begin{array}{c}\text { Modal } \\
\text { kembali }\end{array}$ & 5 th & 20 th \\
\hline $\begin{array}{c}\text { Biaya daur } \\
\text { proses relatif }\end{array}$ & $\$ 4,700$ & $\$ 33,000$ \\
\hline
\end{tabular}

yang menggunakan matahari sebagai sumber energinya, terlihat pada tabel 2 di bawah ini.

9. Skema instalasi penerangan hibrid pada bangunan terlihat pada ilustrasi gbr.5 berikut:

10. Tingkat efisiensi pemanfaatan cahaya matahari pada penerangan hibrid yang mencapai 50-70\% menjadi alternatif potensial untuk digunakan sebagai penerangan bangunan di Indonesia. Hal ini karena kekuatan iluminasi matahari di Indonesia yang berada di garis ekuator sangat besar hampir sepanjang tahun. Berikut data iluminasi cahaya matahari bulanan selama satu tahun, dengan menggunakan data DKI Jakarta:

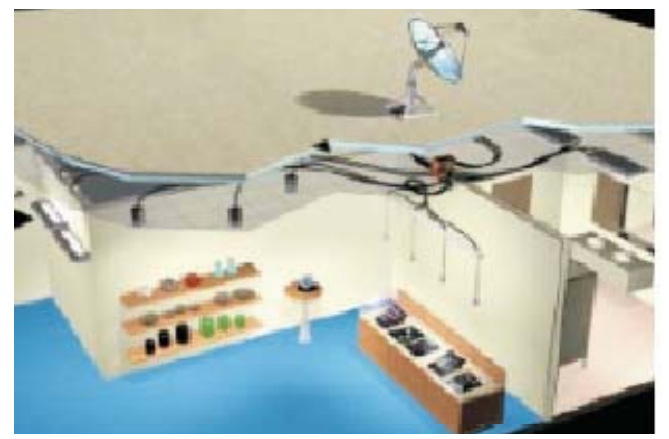

Gambar 5. Instalasi Penerangan Hibrid pada Bangunan

Tabel.3. Data Iluminasi Matahari daerah Khatulistiwa tiap Bulan selama satu tahun (sumber: Muhs, 2004)

\begin{tabular}{|c|c|c|c|c|c|c|c|c|c|c|}
\hline Month & Hour & & & & & & & & & \\
\hline & 8 & 9 & 10 & 11 & 12 & 13 & 14 & 15 & 16 & 17 \\
\hline 1 & 28.6 & 38.2 & 45.7 & 51.4 & 53.7 & 55.2 & 51.8 & 46.8 & 42.1 & 33.1 \\
\hline 2 & 13.7 & 25.4 & 33.9 & 39.8 & 43.9 & 44.4 & 41.1 & 37.3 & 29.1 & 18.3 \\
\hline 3 & 13.8 & 24.7 & 33.5 & 39.5 & 43.1 & 44.1 & 41.8 & 37.7 & 31.4 & 20.1 \\
\hline 4 & 15.9 & 25.0 & 32.3 & 39.5 & 43.1 & 42.2 & 40.6 & 34.9 & 27.2 & 15.9 \\
\hline 5 & 16.6 & 24.1 & 29.7 & 34.4 & 36.2 & 36.1 & 35.4 & 30.3 & 22.1 & 12.7 \\
\hline 6 & 17.9 & 25.4 & 30.0 & 31.1 & 34.6 & 35.3 & 35.8 & 30.1 & 21.0 & 12.4 \\
\hline 7 & 14.4 & 23.5 & 30.7 & 36.4 & 40.5 & 41.7 & 42.8 & 37.3 & 29.2 & 19.2 \\
\hline 8 & 13.8 & 24.0 & 33.0 & 39.1 & 44.1 & 46.2 & 46.1 & 42.6 & 33.2 & 20.7 \\
\hline 9 & 16.4 & 28.0 & 37.5 & 44.7 & 47.3 & 48.3 & 46.0 & 39.1 & 29.0 & 16.8 \\
\hline 10 & 17.3 & 27.9 & 37.2 & 42.2 & 46.2 & 47.2 & 44.7 & 39.4 & 28.7 & 15.8 \\
\hline 11 & 16.2 & 26.6 & 34.7 & 41.4 & 45.5 & 45.6 & 41.6 & 32.8 & 23.2 & 14.7 \\
\hline 12 & 14.4 & 24.4 & 32.5 & 39.2 & 41.8 & 42.4 & 37.8 & 32.0 & 24.0 & 14.7 \\
\hline
\end{tabular}


Teknologi penerangan hibrid yang menggunakan serat optik memiliki beberapa keterbatasan dalam beberapa hal, diantaranya:

1. Efektifitas transmisi cahaya pada kabel serat optik dipengaruhi oleh panjang kabel serat optik. Kemampuan transmisi berkurang rata-rata $15 \%$ per meter panjang. Panjang kabel serat optik yang optimal untuk transmisi cahaya $<20 \mathrm{~m}$, sehingga penerangan hibrid optimal untuk bangunan 2 lantai teratas, bangunan dengan bentuk podium dan bangunan tingkat rendah (low rise) yang memanjang, town house, ruko (rumah toko) dan sangat berguna untuk parkir basement.

2. Keterbatasan panjang kabel serat optik yang optimal untuk instalasi di dalam bangunan dapat dipecahkan dengan kemungkinan pemasangan piringan-piringan pada sisi bangunan per lantai yang menghadap arah lintasan matahari, seperti penggunaan panel Farans (HLVCO,2008).

3. Kemampuan tangkapan cahaya matahari dipengaruhi oleh faktor cuaca, seperti tutupan awan, hujan, asap. Sehingga penerangan hibrid perlu dikombinasikan dengan penerangan listrik untuk substitusi penerangan ruangan disaat cuaca di luar tidak memungkinkan untuk memperoleh tangkapan cahaya matahari yang maksimal.

\section{KESIMPULAN}

Teknologi penerangan hibrid sudah saatnya untuk diterapkan di Indonesia, sebagai sebuah alternatif penerangan bangunan yang hemat energi dan pemanfaatan energi terbarukan sinar matahari. Hal ini dengan mempertimbangkan faktor-faktor:
1. Letak geografis Indonesia di daerah khatulistiwa yang mendapat cahaya matahari dengan tingkat iluminasi yang sangat besar dan berlangsung hampir sepanjang tahun.

2. Perhitungan ekonomi penerangan hibrid berdasarkan beberapa penelitian dan aplikasi yang telah dilakukan menunjukkan penerangan hibrid mempunyai tingkat efisiensi dari sisi energi, modal, biaya instalasi serta investasi.

3. Penerangan hibrid memberikan keleluasaan aplikasi dan pengembangan inovasi penerangan bangunan yang memanfaatkan energi matahari.

\section{DAFTAR PUSTAKA}

1. Soydan Y \& T en Gin, 2002.,"'Lighting Building Interiors Requiring Lighting at Day Times by Conveying Daylight", Journal Departement of Mechanical Engineering Sakarya University, Esentepe, Turkey.

2. Fay, Charles., 2002, "Daylighting and Productivity: A Literature Review", The Lighting Research Center, Rensselaer Polytechnic Institute, New York

3. J.D. Muhs, 2000, "Design and Analysis of Hybrid Solar Lightýng and Full-Spectrum Solar Energy Systems", Presented at The American Solar Energy Society's, Solar 2000 Conference, Wisconsin

4. Maxey, Curt., 2008," Fiber Optics Brings Sunlight Inside. Photonics Spectra. Laurin Publication.

5. Lapsa, Melissa Voss, et al., 2006," Innovative Hybrid Solar Lighting Reduces Waste Heat and Improves Lighting Quality". Oak Ridge: Oak Ridge National Laboratory. 
6. Earl, Duncan D and Jeff D Muhs., 2002, "Modelling and Evaluation of Chromatic Variations in a Hybrid Solar/ Electric Lighting System". Technical Report. Oak Ridge, TN: Oak Ridge National Laboratory.

7. Wood, Byard D. and David L Beshears., 2006, "Adaptive FullSpectrum Solar Energy Systems: Cross-Cutting R\&D on adaptive fullspectrum solar energy systems for more efficient and affordable use of solar energy in buildings and hybrid photobioreactors", Report SemiAnnual Technical Progress Report: For period ending January 31, 2006. Oak Ridge National Laboratory. Knoxville, TN: U.S. Dept. of Energy.
8. Muhs, Jeff D, Byard Wood and Rob Taylor., 2004, "The Sunlight Inside Initiative. Oak Ridge, TN: Oak Ridge National Laboratory. 